\title{
Assessment of Knowledge of Various Aspects of Covid-19 among Undergraduate Dental Students of Pakistan: A Brief Survey
}

\section{Muneeb Ahmed, Azeem Ur Rahman Khan, Ahsan Shaffat Khan}

FMH College of Medicine and Dentistry, Lahore, Pakistan.

*Corresponding Author: Muneeb Ahmed, FMH College of Medicine and Dentistry, Lahore, Pakistan.

\begin{abstract}
Background: The outbreak of Corona Virus Disease 2019 (COVID-19) and the given nature of the virus how easily it may spread from one individual to other and through common dental procedures via aerosols, has resulted in shutting down of approximately 198,000 active dentists and dental specialists in USA.

Materials and Method: One thousand dental students of BDS first year to final year were enrolled in the study. The questionnaire consisting of COVID 19 related questions was distributed to the students and all of subjects replied back. Questionnaire included ten questions in order to collect information about the various aspects of COVID 19,
\end{abstract}

Statistical Analysis: Statistical analysis of data was performed using Statistical Package for Social Sciences (SPSS Inc. Chicago, IL, version 16.0).

Results and Observations: Out of 1000, 450 were males and 550 students were females. All the participants have heard about the pandemic. Ninety six percent had knowledge about the etiology of the disease, $74 \%$ were familiar that it spreads by aerosols. It was found out that majority of the participants (86\%) had knowledge of importance of social distancing in preventing the spread of the disease. 47\% participants reported that COVID 19 is common in children as compared to old age.

Conclusion: The results of the study reported that dental students had knowledge about various aspects of COVID-19. Because of the limited sample size and parameters of the present study, future studies with larger sample sizes are warranted. The attitude and practices of dental students should also be assessed in future studies.

\section{INTRODUCTION}

The outbreak of Coronavirus Disease (COVID-19) and the given nature of the virus how easily it may spread from one individual to other and through common dental procedures via aerosols [1], has resulted in shutting down of approximately 198,000 active dentists and dental specialists in the USA. Most of the dentists in Pakistan are also facing similar problems as indicated by Pakistan Health Authorities. This may lead to serious problems as suggested by various oral health care agencies. Delayed dental care has a variety of consequences, whether it is due to dental office closures, reluctance to seek care during a pandemic, loss of employer-sponsored dental insurance coverage, or other factors. Routine dental visits are opportunities to provide preventive oral health care (e.g., fluoride treatment and sealants) and to identify oral manifestations of systemic disease that might otherwise be missed. A lack of access to routine dental care can also lead to untreated tooth decay or other infections, leaving people with no viable option other than visiting a hospital emergency department, where treatment is costly and can disrupt more urgent needs, especially during a pandemic. In addition, many emergency departments are not staffed or equipped to provide definitive dental treatment and instead 
Assessment of Knowledge of Various Aspects of Covid-19 among Undergraduate Dental Students of Pakistan: A Brief Survey

only provide patients with temporizing measures such as prescriptions for short-term treatment of pain and/or infection until definitive care can be provided elsewhere[2]. For countries like Pakistan, where most of the dental clinics operate with just basic facilities specially in remote areas and villages, it has become very difficult for dentists to meet all the requirements as suggested by dental council to prevent spread of the pandemic because the equipment cost has increased multifold but the income has been reduced significantly. Keeping in mind the effects of COVID 19 on dental practice, it has become really important to assess the knowledge of our budding dentists or dental students on this issue. This survey is such an attempt and in this the knowledge and attitude of dental Table1. Questionary students of Pakistan has been assessed regarding the predisposing factors, causes and prevention of this pandemic.

\section{Materials AND Method}

This study evaluated the views and attitude of dental students regarding COVID 19 pandemic. Data was collected through a survey (in the form of questionnaire) from the dental students. One thousand dental students of BDS first year to final year were enrolled. The questionnaire was distributed to all and all of them replied back. Questionnaire included ten questions in order to collect information about the various aspects of COVID 19, [Table 1]

\begin{tabular}{|l|l|l|}
\hline Sr. No. & Question & Year: Reply yes/no/no comment \\
\hline 1. & Do you know about COVID-19? & \\
\hline 2. & Does it spread by aerosols? & \\
\hline 3. & Is it a viral disease? & \\
\hline 4. & Can it be prevented by social distancing? & \\
\hline 5. & Is it more common in children than old age? & \\
\hline 6. & $\begin{array}{l}\text { Is it the responsibility of the government or individual to } \\
\text { prevent its spread? }\end{array}$ & \\
\hline 7. & Have your studies been affected by it? & \\
\hline 8. & Have your clinical work affected by it? & \\
\hline 9. & $\begin{array}{l}\text { How would you like to provide knowledge to people about } \\
\text { this disease? Write in brief. }\end{array}$ & \\
\hline 10. & An other points you would like to mention? & \\
\hline
\end{tabular}

Prior to data collection the questions were pretested among a group of 20 professionals in order to ensure the level of validity and degree of repeatability (Cronbach's alpha $=0.76)$. Statistical analysis of data was performed using statistical package for social sciences (SPSS Inc. Chicago, IL, version 16.0).

\section{OBSERVATION AND RESULTS}

A total of 1000 dental students participated in this study consisting of 250 from each batch of BDS from first to final year. Out of 1000, 450 were males and 550 students were females. All the participants have heard about the pandemic. Ninety six percent knew that it is a viral disease, $74 \%$ were familiar that it spreads by aerosols. It was found out that majority of the participants (86\%) had knowledge of importance of social distancing in preventing the spread of the disease. Thirty seven percent participants said that
COVID 19 is common in children as compared to old age. Twenty three percent believed that its the governments responsibility to control the disease. Most of the dental students (90\%) reported that it has affected their clinical work, where only $12 \%$ reported that COVID 19 had affected their academic work. Most of the students believed that social media should be used to create awareness about the prevention of this disease.

\section{Discussion}

According to that reported by the New York Times [3], dentistry is one of the most exposed professions to the COVID-19 contagion. It is imperative to plan a clinical protocol to be applied in the working environment to avoid new infections and progressive virus spread. The dentists and dental axillaries are at a higher risk of this disease. Therefore, the use of disinfectants 
Assessment of Knowledge of Various Aspects of Covid-19 among Undergraduate Dental Students of Pakistan: A Brief Survey

and personal protection equipment has become mandatory for dental practitioners[4]. Moreover any patients with signs and symptoms of the disease should not to be treated until tested. But in cases of any dental emergencies the patient can be treated with all the preventive measures to prevent the spread of the disease from patient to dental staff.

Results of the survey revealed that most of the students had knowledge about this disease. But it was surprising to know that most of the students reported that COVID 19 is more common in children in comparison to adults. In actuality, the disease is common in old age groups, this may be attributed to weak immune system in old age and other systemic diseases may also predispose to this infection. Despite of so many awareness programs about this infection, this response of students revealed lack of knowledge about this aspect. Some students (37\%) believed that its only the responsibility of the governments to control the spread of this infection. Remaining $63 \%$ reported it as personal duty. It was good that students know their responsibilities in limiting the spread of the disease but still some more awareness about this is required. Greater percentage of the students reported that the clinical work has been impacted to a larger extent by COVID 19 in comparison their academic work. This may be attributed to the fact that the academic activities are continuing using online classes and other online portals in most of the institutes but in order to prevent the spread of the disease the clinical classes or activities has been suspended in most of the dental schools, or a limited number of persons are allowed to work at a particular time. This may be the reason that clinical work has been impacted. Taking this aspect in consideration some special steps should be taken so that students can get adequate clinical practice and enhance their skills [5].

Regarding the method of creating awareness, all the students reported that social media could be the best possible way to target audience. This could be in any form i.e facebook, instagram and other platforms. This give us an indication about the indulgence of dental students toward social media. Although many people use these platforms to interact with people but in country like Pakistan, in remote area people do not have access to these social media platforms, some even do not have mobile phones. So to make the awareness programs effective all the possible methods which could be employed such as Television, Radio, Newspapers, Posters etc, so that maximum number of people can be educated about this infection and the spread of this disease can be controlled [5].

This study evaluated the knowledge of dental students about various aspects of COVID-19, but it also had some limitations. The comparison among knowledge of different groups of BDS students has not been made, the attitude and practice is also not evaluated , which would have helped to find out how many dental students personally follow the guidelines to prevent the spread of this infection. For studying a pandemic, the sample size seems smaller. It is imperative to follow and practice the guidelines issued by health authorities in order to prevent this pandemic. All the practices such as use of facemasks, social distancing, not going to crowded places, should be practiced and implemented with strictness.

\section{ConCLusion}

The results of the study reported that dental students had knowledge about various aspects of COVID-19. Because of the limited sample size and parameters of the present study, future studies with larger sample sizes are warranted. The attitude and practices of dental students should also be assessed in future studies.

\section{REFERENCES}

[1] Chen, N, Zhou, M, Dong, X, Qu, J, Gong, F, Han, Y, Qiu, Y, Wang, J, Liu, Y, Wei, Y, et al. Epidemiological and clinical characteristics of 99 cases of 2019 novel coronavirus pneumonia in Wuhan, China: a descriptive study. Lancet 2020; 395(10223):507-513

[2] Backer, JA, Klinkenberg, D, Wallinga, J. 2020. Incubation period of 2019 novel coronavirus (2019-nCoV) infections among travellers from Wuhan, China, 20-28 January 2020. Euro Surveill. 25(5). 
Assessment of Knowledge of Various Aspects of Covid-19 among Undergraduate Dental Students of Pakistan: A Brief Survey

[3] Gamio L. The Workers Who Face the Greatest Coronavirus Risk. New York Times, 15 March 2020. [(accessed on 5 April 2020)]; Available online: https://www.nytimes.com/ interactive/2020/03/15/business/economy/ coronavirus-worker-risk.html.

[4] Luzzi V., Ierardo G., Bossù M., Polimeni A. COVID-
19: Pediatric Oral Health during and after the Pandemics. Appl. Sci. 2020;10:1-8. doi: 10.20944/preprints202004.0002.v1.

[5] Jashneek K. Awareness of COVID 19 among Indian Dental Students: A brief Survey. MAR Dental Sciences 1;4:2020.

Citation: Muneeb Ahmed, Azeem Ur Rahman Khan, Ahsan Shaffat Khan. Assessment of Knowledge of Various Aspects of Covid-19 among Undergraduate Dental Students of Pakistan: A Brief Survey. Archives of Dentistry and Oral Health. 2020; 3(2): 15-18.

Copyright: (C) 2020 Muneeb Ahmed, Azeem Ur Rahman Khan, Ahsan Shaffat Khan. This is an open access article distributed under the Creative Commons Attribution License, which permits unrestricted use, distribution, and reproduction in any medium, provided the original work is properly cited. 